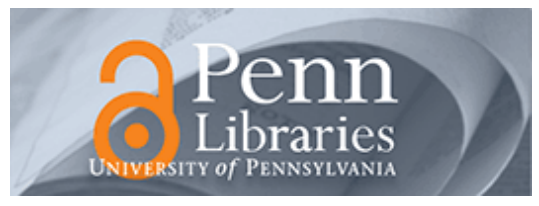

University of Pennsylvania ScholarlyCommons

\title{
Blockholder Trading, Market Efficiency, and Managerial Myopia
}

Alex Edmans

University of Pennsylvania

Follow this and additional works at: https://repository.upenn.edu/fnce_papers

Part of the Finance Commons, and the Finance and Financial Management Commons

\section{Recommended Citation}

Edmans, A. (2009). Blockholder Trading, Market Efficiency, and Managerial Myopia. The Journal of Finance, 64 (6), 2481-2513. http://dx.doi.org/10.1111/j.1540-6261.2009.01508.x

This paper is posted at ScholarlyCommons. https://repository.upenn.edu/fnce_papers/293

For more information, please contact repository@pobox.upenn.edu. 


\title{
Blockholder Trading, Market Efficiency, and Managerial Myopia
}

\author{
Abstract \\ This paper analyzes how blockholders can exert governance even if they cannot intervene in a firm's \\ operations. Blockholders have strong incentives to monitor the firm's fundamental value because they can \\ sell their stakes upon negative information. By trading on private information (following the "Wall Street \\ Rule"), they cause prices to reflect fundamental value rather than current earnings. This in turn \\ encourages managers to invest for long-run growth rather than short-term profits. Contrary to the view \\ that the U.S.'s liquid markets and transient shareholders exacerbate myopia, I show that they can \\ encourage investment by impounding its effects into prices. \\ Disciplines \\ Finance | Finance and Financial Management
}




\title{
Blockholder Trading, Market Efficiency, and Managerial Myopia
}

\author{
Alex Edmans* \\ (forthcoming in the Journal of Finance)
}

\begin{abstract}
This paper analyzes how blockholders can exert governance even if they cannot intervene in a firm's operations. Blockholders have strong incentives to monitor the firm's fundamental value, since they can sell their stakes upon negative information. By trading on private information (following the "Wall Street Rule"), they cause prices to reflect fundamental value rather than current earnings. This in turn encourages managers to invest for longrun growth rather than short-term profits. Contrary to the view that the U.S.'s liquid markets and transient shareholders exacerbate myopia, I show that they can encourage investment by impounding its effects into prices.
\end{abstract}

${ }^{*}$ The Wharton School, University of Pennsylvania. I am deeply grateful to my advisors, Stewart Myers, Dirk Jenter, Gustavo Manso, and Xavier Gabaix for their support and guidance. I am indebted to an anonymous referee for numerous comments that significantly improved the paper, as well as an associate editor and the editor, Cam Harvey. This paper has also benefited from input by Prasun Agarwal, Franklin Allen, Jack Bao, Indraneel Chakraborty, Florian Ederer, Isil Erel, Chris Evans, Carola Frydman, Itay Goldstein, Li He, Cliff Holderness, Adam Kolasinski, Pavitra Kumar, Robert Marquez, Anna Obizhaeva, Weiyang Qiu, Robert Ready, Michael Roberts, Steve Ross, Alan Schwartz, Jeremy Stein, Luke Taylor, Masako Ueda, Jialan Wang, Paul Yan, and seminar participants at the 2008 Penn/NYU Conference on Law and Finance, the 2007 WFA meetings, the 2006 CEPR European Summer Symposium in Financial Markets, the 2006 FMA doctoral tutorial, Berkeley, Boston College, Dartmouth, Duke, Maryland, MIT, Northwestern, Notre Dame, NYU, UBC, UCLA, UNC, Wharton, and Yale. I acknowledge excellent research assistance from Qi Liu, and travel grants from the NYSE and the MIT Graduate Student Council. This paper was previously circulated as "Blockholders, Market Efficiency, and Managerial Myopia." 
"The nature of competition has changed, placing a premium on investment in increasingly complex and intangible forms - the kinds of investment most penalized by the U.S. [capital allocation] system." - Porter (1992)

This PAPER ANALYZES how outside blockholders can induce managers to undertake efficient real investment through their informed trading of the firm's shares. By gathering information about a firm's fundamental value and impounding it into prices, they encourage managers to undertake investment that increases long-run value even if it reduces interim profits. The model therefore addresses two broad issues. First, it introduces a potential solution to managerial myopia. Second, it demonstrates that shareholders can add significant value even if they cannot intervene in a firm's operations. This may explain the prevalence in the U.S. of small transient blockholders, who typically lack control rights and instead follow the "Wall Street Rule" of "voting with their feet" - selling their stock if dissatisfied.

Many academics and practitioners believe that myopia is a first-order problem faced by the modern firm. In the last century, firms were predominantly capital-intensive, but nowadays competitive success increasingly depends on intangible assets such as human capital and R\&D capabilities (Zingales (2000)). Building such competencies requires significant and sustained investment. Indeed, Thurow (1993) argues that investment is an issue of national importance that will critically determine the U.S.'s success in global competition.

However, managers may fail to invest if they are concerned with the firm's short-term stock price. Since the benefits of intangible investment are only visible in the long run, the immediate effect of such investment is to depress earnings. Indeed, Graham, Harvey, and Rajgopal's (2005) survey finds that $78 \%$ of executives would sacrifice long-term value to meet earnings targets. Moreover, the recent rise in equity-based compensation ${ }^{1}$ (Murphy (2003)) and the sensitivity of CEO turnover to the stock price (Kaplan and Minton (2006)) has likely increased managers' myopic tendencies.

While previous papers have focused on various causes of myopia, this paper analyzes a solution: blockholders. A blockholder has strong incentives to gather costly information about the firm's fundamental value, that is, to learn whether weak earnings result from low firm quality or desirable long-term investment. ${ }^{2}$ If the cause is low quality, the blockholder profits by selling her stake, depressing the stock price. If the cause is desirable investment, she does not sell, which attenuates the stock price decline caused by weak earnings. In both cases, the blockholder causes stock prices to reflect fundamental value rather than short-term earnings. This increased market efficiency improves real efficiency: the manager is willing to undertake investments that boost fundamental value even if they depress short-term earnings. The Wall Street adage

\footnotetext{
${ }^{1}$ Equity compensation would not induce myopia if it had very long vesting periods. However, vesting periods are often short in practice (Kole (1997), Johnson, Ryan, and Tian (2009)), perhaps because very long vesting periods would subject the manager to high risk.

2 "Investment" can encompass any action that enhances firm value, but worsens outsiders' perceptions in the short run. "Low investment" can therefore represent accounting manipulation to improve outsiders' short-term perceptions. Blockholders can deter such manipulation as they can "see through" the numbers and will sell if high earnings are not backed up by strong fundamentals.
} 
that the "market sells first and asks questions later" does not apply to blockholders: owing to their sizable holdings, they have the incentive to ask questions first and not automatically sell upon losses. A noted real-life example is Warren Buffett, who typically acquires blocks in companies with significant growth opportunities. His investment shields the firm from stock market concerns, helping it to focus on long-term value.

In sum, while the blockholder's monitoring and trading is motivated by her private desire to earn profits at the expense of liquidity investors, they have real social benefits by inducing efficient investment. But why does such monitoring and trading have to be undertaken by blockholders? Many empirical studies use block size as a proxy for investor sophistication, assuming that large investors have greater incentives to become informed (see Boehmer and Kelley (2009) and Rubin (2007) for recent examples). Although this concept appears intuitive, it is not delivered in standard informed trading models since an investor's ability to trade on information is independent of her stake. The model introduces a short-sales constraint to provide a framework underpinning the assumed positive link between block size and information. If short sales are prohibited (or sufficiently costly), the only way to profit from bad news is to sell an existing position. The larger the initial holding, the more the blockholder can sell upon negative information, and so the greater the incentives to collect information in the first place.

The role of blockholders in this paper differs from prior models, where they add value through direct intervention such as forcing a restructuring or vetoing a pet project. ${ }^{3}$ This paper shows that blockholders can improve firm value even if they are unable to intervene (engage in "voice") and can only trade (engage in "exit"). This departure from the literature is empirically motivated. Blockholders in the U.S. rarely intervene, because they are typically small $^{4}$ and face significant legal and institutional barriers. ${ }^{5}$ Existing models thus have difficulty in explaining the role that such blockholders play in corporate governance, and thus justifying why they are so prevalent. ${ }^{6}$ Moreover, the lack of large blockholders and consequent rarity of intervention may suggest that U.S. firms are poorly governed and that policy action is desirable. This paper offers an alternative perspective - blockholders can still exert governance even if they lack control rights. In addition to evidence on the barriers to intervention, there is also

\footnotetext{
${ }^{3}$ Examples include Shleifer and Vishny (1986), Burkart, Gromb and Panunzi (1997), Pagano and Roell (1998), Kahn and Winton (1998), Bolton and von Thadden (1998), Maug (1998, 2002), Aghion, Bolton, and Tirole (2004), Faure-Grimaud and Gromb (2004), and Brav and Mathews (2008).

${ }^{4}$ When blockholders are defined as $5 \%$ shareholders, Holderness (2009) finds that $96 \%$ of U.S. firms contain a blockholder. However, when the minimum ownership is defined as 20\%, La Porta, Lopez-de-Silanes, and Shleifer (1999) document that 20\% (10\%) of large (medium) U.S. firms contain a blockholder. They estimate that a $20 \%$ stake gives effective control if the shareholder is an insider; the threshold is likely to be higher for outside shareholders. Hence, blockholders are prevalent in the U.S., but tend to lack control rights. Holderness finds that concentrated blockholders with board seats tend to be families. This paper focuses on financial blockholders who typically hold smaller stakes and have less frequent board representation.

${ }^{5}$ See Becht et al. (2008) and Black (1990)) for details of such barriers. Armour et al. (2007) document that U.S. shareholders seldom engage in litigation, and rarely succeed if they do; the same is true for the proxy fight mechanism. As Lowenstein (1988) writes: "[Institutional investors] implicitly praise or criticize management, by buying or selling, but seldom get involved more directly, even to the extent of a phone call. There is almost no dissent from the Wall Street Rule."

${ }^{6}$ Similarly, intervention models would imply little role for holders of non-voting shares, even if they have large stakes. This paper shows that such investors can improve firm value by their trading behavior.
} 
research on the real-life importance of governance through trading. The survey evidence of McCahery, Sauntner, and Starks (2008) finds that institutions use "exit" more frequently than any other governance mechanism, and Parrino, Sias and Starks (2003) document direct evidence of this channel.

The analysis of different governance mechanisms (exit versus voice) leads to different results regarding the optimal block size for firm value and the effect of liquidity on governance. In a number of theories of voice, a larger block is always desirable as it increases monitoring and intervention incentives. Here, block size has a non-monotonic effect on firm value. Trading profits depend not on block size per se, but on the amount sold upon bad news. If the block becomes too large, market liquidity declines and the blockholder cannot sell her entire stake. Since her potential trading profits are lower, she acquires less information, so prices are less efficient. This finite optimum is consistent with the paucity of large blockholders in the U.S. (La Porta, Lopez-de-Silanes, and Shleifer (1999)). Large stakes may not only be unnecessary for a blockholder to exert governance, but also undesirable.

The second difference from prior research concerns the desirability of liquidity. Motivated by several intervention theories, Bhide (1993) argues that, since blockholders add value through voice, and voice and exit are mutually exclusive, liquidity is harmful as it allows a shareholder to leave rather than intervene. In this paper, the blockholder adds value through "loyalty" to a fundamentally sound firm that suffers weak short-term earnings. Loyalty and exit are similarly mutually exclusive and so it may seem that liquidity is again undesirable, since it allows shareholders to sell easily upon weak earnings, causing managers to focus excessively on earnings. Indeed, Porter (1992) and Thurow (1993) argue that the U.S.'s liquid markets deter long-run investment, potentially endangering the U.S.'s future international competitiveness. They advocate policies to reduce liquidity and thus create unconditionally long-run shareholders who never sell.

However, this paper shows that the mutual exclusivity of loyalty and exit paradoxically leads to complementarities between them. If a blockholder has retained her stake despite low earnings, this is a particularly positive indicator of fundamental value if she could easily have sold instead. In short, the power of loyalty relies on the threat of exit. The result that blockholders promote long-run behavior does not stem from simply assuming that blockholders are unconditionally long-run investors who never sell. Indeed, an investor's loyalty upon bad news is uninformative if market illiquidity prevented her from exiting anyway. Instead, conditional loyalty and the threat of short-term selling can, surprisingly, promote long-term investment. Far from exacerbating myopia, the liquidity of the U.S. capital allocation system may be a strength. This implication may explain why the above fears for the U.S.'s global competitiveness have not been borne out. Consistent with the model, Fang, Noe and Tice (2008) document a causal relationship between liquidity and firm performance, which arises because liquidity leads to greater price efficiency.

This result builds on Maug (1998), who overturned earlier papers arguing that liquidity is undesirable in an intervention setting by pointing out that they assume an exogenous block size. Maug shows that when block size is endogenous, liquidity is beneficial since it encourages 
a larger block to form in the first place. In the present paper, liquidity has a second benefit - it leads to increased liquid trading by these blocks, once formed. While such trading is harmful in an intervention framework (and so the benefits of liquidity stem entirely from their effect on initial block size), in an exit model it is the very mechanism through which the blockholder adds value. Hence, increasing liquidity from low levels is beneficial even if block size is exogenous and does not rise in response to greater liquidity. ${ }^{7}$ Here, liquidity is desirable not only for the reason introduced by Maug, but also because it leads to more liquid trading. This conclusion is potentially important because disclosure requirements or regulation may restrict block size from rising in response to liquidity (see, for example, Roe (1994)) and prevent the first benefit from being obtained. Indeed, in the U.S., ownership is fragmented despite high liquidity, suggesting that these forces may be important. Even if this is the case, liquidity can be valuable.

While the paper's main result is that blockholders can encourage investment, the corollary is that a key cost of the U.S.'s dispersed ownership is myopia. This leads to an additional policy implication. Previous papers argue that the main problem with atomistic shareholders is that they lack the control rights to intervene and thus allow the manager to shirk (e.g., Roe (1994)). In this case, potential solutions to dispersed ownership are equity compensation and regulations against takeover defenses. However, if the main cost is that dispersed shareholders focus on current earnings and thus induce myopia, these policies exacerbate the issue. The problem with small shareholders may not be so much the "separation of ownership from control" (Berle and Means (1932)) as the "separation of ownership from information."

The paper closes with empirical implications. One set concerns stock price effects, and is unique to a model in which blockholders trade rather than intervene. While block size does not matter in standard microstructure theories, here it is positively correlated with an investor's private information, trading profits, and price efficiency. Existing empirical studies typically use institutional ownership as a measure of investor informativeness, but the model suggests that block size may be more relevant, since sizable stakes are necessary to incentivize investors to gather information. Bushee and Goodman (2007) and Parrino, Sias and Starks (2003) indeed find larger shareholders are more informed. More generally, the model suggests a shift in focus in the way we think about blockholders that can give rise to new directions for empirical research. Previous studies have been primarily motivated by perceptions of blockholders as controlling entities (e.g., Barclay and Holderness (1989, 1991)), but new research questions may be motivated by conceptualizing them as informed traders. (See Brockman and Yan (2009) and Gallagher, Gardner, and Swan (2008) for two recent such papers.) A second set relates to real effects: blockholders should increase firm investment (Cronqvist and Fahlenbrach (2009)), and deter earnings manipulation (Dechow, Sloan, and Sweeney (1996), Farber (2005), Burns, Kedia, and Lipson (2008)). These predictions distinguish the model from theories where the blockholder solves managerial shirking or the pursuit of pet projects, rather than myopia.

\footnotetext{
${ }^{7}$ When block size is exogenous, the optimal liquidity is finite because too much liquidity camouflages the blockholder's trades and reduces price informativeness. With endogenous stakes, increasing liquidity is desirable even at high levels since block size increases with liquidity to prevent such camouflage.
} 
Admati and Pfleiderer (2009) also analyze a blockholder who can only engage in exit rather than voice. Our papers focus on fundamentally different agency problems: while Admati and Pfleiderer analyze effort (broadly defined to incorporate both shirking and free cash flow problems), I study investment, in particular, whether it is deterred by liquid trading as commonly believed. While the effort conflict may have been attenuated by recent increases in the manager's sensitivity to the stock price, such changes further exacerbate myopia. A second difference is that Admati and Pfleiderer assume that the blockholder is exogenously informed, and so the level of monitoring is fixed. This paper endogenizes costly information gathering and generates testable predictions regarding the effect of block size on monitoring and trading, and in turn market efficiency, real investment, and firm value. By contrast, Admati and Pfleiderer focus on the nature of the agency problem and derive the interesting result that while the blockholder always attenuates free cash flow problems, she sometimes exacerbates shirking.

The beneficial effect of ex post monitoring on ex ante investment is shared by Edmans (2007). Debt concentrates equityholders' stakes, incentivizing them to discover the cause of interim losses. Thus, debt can allow liquidation of an incompetent manager who suffers shortterm losses, without simultaneously deterring skilled managers from long-term projects that risk such losses. While Edmans (2007) is a theory of capital structure that assumes intervention, this paper is a theory of ownership structure in which the blockholder can only trade.

In Holmstrom and Tirole (1993), increased market efficiency allows prices to more accurately reflect managerial effort, increasing the optimal sensitivity of pay to the stock price. In their model, monitoring is performed by atomistic shareholders and they do not consider blockholders as potential monitors - hence, blocks reduce price efficiency via their negative effect on liquidity. I show that blockholders may be particularly important monitors as they have the strongest incentives to gather the intangible information that is especially relevant for long-term investment. Without blockholders, the stock price primarily reflects publicly available current earnings. Thus, tying the manager's pay to the firm's stock price can induce myopia.

A final strand of related literature concerns insider trading by management, which can also increase financial and real efficiency (e.g., Manne (1966)). The blockholder is likely to be significantly more effective than the manager at impounding information into prices for several reasons. First, managers are constrained by insider trading laws, personal wealth (limiting purchases), or lock-ups of stock as part of incentive packages (limiting sales). Second, the manager may be conflicted since the stock price is used to evaluate him, and so may choose not to reveal negative private information by selling shares. Third, conflicts may also arise because the manager has control over the information flow and investment decisions (Bernhardt, Hollifield, and Hughson (1995)). He may release false negative (positive) information and subsequently buy (sell) shares, or sell his shares and take the incorrect investment decision. One paper that does analyze insider trading by the blockholder is Maug (2002), who shows that legalizing such actions can induce her to exit rather than engage in value-enhancing intervention.

This paper is organized as follows. Section I introduces the basic model, which links block size to financial efficiency. Section II presents the core result of the paper by introducing man- 
agerial decisions and illustrating the impact on real efficiency. Section III discusses empirical predictions and Section IV concludes. The Appendix contains all proofs not in the main paper.

\section{Blockholders and Market Efficiency}

This section analyzes the effect of block size on monitoring and stock prices. The real consequences are studied in Section II, where managerial decisions are introduced.

I consider a firm with one share outstanding. A blockholder $(B)$ owns $\alpha$ units and atomistic shareholders collectively own the remaining $1-\alpha$ units. All agents are risk-neutral and the risk-free rate is normalized to zero. There are three periods, summarized in Figure 1. At $t=1$, a public signal $s \in\left\{s_{g}, s_{b}\right\}$, such as an earnings announcement, is released. The signal is imperfectly informative about the firm's fundamental value $V$, which is revealed at $t=3$. If $s=s_{g}, V=X>0$ with certainty; if $s=s_{b}, V=0$ or $X$ with equal probability. I refer to a firm with $V=X(0)$ as a "high (low)-quality firm;" $s=s_{g}$ is a "good signal" and $s=s_{b}$ is a "bad signal" (also referred to in the text as "losses" or "low earnings").

\section{[Insert Figure 1 about here]}

At $t=2, B$ exerts monitoring effort $\mu \in[0,1]$ at cost $\frac{1}{2} c \mu^{2}$. Monitoring gives $B$ a private signal $i \in\left\{i_{g}, i_{b}\right\}$ of $V$, the precision of which rises with $\mu$ as follows:

$$
\begin{aligned}
& \operatorname{Pr}\left(i_{g} \mid X\right)=\operatorname{Pr}\left(i_{b} \mid 0\right)=\frac{1}{2}+\frac{1}{2} \mu \\
& \operatorname{Pr}\left(i_{g} \mid 0\right)=\operatorname{Pr}\left(i_{b} \mid X\right)=\frac{1}{2}-\frac{1}{2} \mu .
\end{aligned}
$$

The posterior probabilities that the firm is of high quality are thus given by

$$
\begin{aligned}
& \operatorname{Pr}\left(X \mid i_{g}\right)=\frac{1+\mu}{2} \\
& \operatorname{Pr}\left(X \mid i_{b}\right)=\frac{1-\mu}{2}=\pi_{b} .
\end{aligned}
$$

If $\mu=0$, private information is completely uninformative and the posterior equals the prior $\frac{1}{2}$; if $\mu=1, B$ knows $V$ with certainty. There is then a round of trading. The blockholder either demands nothing $(b=0)$ or sells $\beta$ units $(b=-\beta)$; she sells if she receives signal $i_{b}$ and holds otherwise. ${ }^{8}$ I assume $\beta \leq \alpha$ owing to short-sales constraints, since this paper's focus is

\footnotetext{
${ }^{8}$ The core analysis involves the blockholder selling or holding, since this paper's focus is the Wall Street Rule: the shareholder exit that is widely believed to exacerbate myopia. The results are unchanged by allowing the blockholder to buy a fixed amount regardless of her initial stake. While the incentives to buy are unaffected by $\alpha$, the ability to sell remains (non-monotonically) increasing in $\alpha$. Hence, overall profits from information, and thus monitoring incentives, remain non-monotonically increasing in $\alpha$. The results are in the Internet Appendix, available at www.afajof.org.
} 
non-interventionist financial blockholders such as mutual funds, pension funds, and insurance companies, the vast majority of which are unable to sell short. The model's results continue to hold under nontrivial short-sales costs, as discussed in Section I.A.

Also at $t=2$, liquidity traders demand $u$, where $u$ is exponentially distributed, that is,

$$
f(u)=\left\{\begin{array}{l}
0 \text { if } u \leq 0 \\
\lambda e^{-\lambda u} \text { if } u>0,
\end{array}\right.
$$

where $\lambda=\frac{1}{\nu(1-\alpha)}$ and $\nu \leq 1$ is a liquidity parameter. The competitive market maker sees total demand $d=b+u$ and sets a price $P$ equal to the conditional expectation of $V$ given $d$ and $s$, similar to Kyle (1985).

The parameter $\nu$ captures factors other than free float $(1-\alpha)$ that affect liquidity, such as transaction costs, taxes, disclosure requirements, and other regulations. Since the mean liquidity trade is $E(u)=\frac{1}{\lambda}$, we have the standard feature that the volume of liquidity trades is increasing in the amount held by small shareholders $(1-\alpha)$, since liquidity trades often emanate from current investors. While liquidity trades are literally modeled as purchases, all of the model's results continue to hold if the distribution of liquidity trades is transposed downwards, so that the bulk of such trades are sales. Since only current shareholders can sell the stock, there is a clear connection between free float and liquidity. This linkage remains under the literal interpretation of liquidity trades as purchases. Current shareholders are likely to be more informed about a particular stock than non-shareholders, and thus more likely to be purchasers if there is ambiguity aversion, or if non-shareholders do not know about the stock's existence - see Merton (1987) for a model in which investors are restricted to buy stocks that they know about. In Bolton and von Thadden (1998), Kahn and Winton (1998), and Holmstrom and Tirole (1993), liquidity purchases also stem from existing owners.

The exponential distribution of $u$, also used in Barlevy and Veronesi (2000), is used for tractability as it allows $B$ 's sale volume to be derived in closed form. (The key idea that block size affects the ability to sell on negative information, and thus monitoring incentives, does not depend on the functional form for $u$ ). Kyle (1985) achieves tractability with normal liquidity trader demand as firm value is also normal. In most corporate finance models featuring the Kyle model, firm value is binary and so the informed trader's order cannot be solved for; such papers therefore typically restrict her trade to exogenous amounts. The exponential distribution in this paper allows her trade to be endogenously derived as a function of block size.

\section{A. Market Equilibrium}

If signal $s_{g}$ is emitted, the market maker knows that the firm is of high quality, and so sets $P=X$. Since the signal is fully revealing, $B$ has no incentives to monitor or trade. The remainder of this section focuses on the interesting case of $s=s_{b}$, and so "| $s_{b}$ " notation is omitted for brevity. Since the signal is not fully revealing, $B$ does monitor and trade, and the market maker tries to infer $B$ 's information from total order flow $d$. 
Lemma 1 below presents the Nash equilibrium, where $B$ 's trading and monitoring decisions are optimal given the market maker's pricing function, and the market maker's pricing function earns him zero profit given $B$ 's decisions. I assume $X \leq 8 \mathrm{c}$ to ensure that effort does not exceed the maximum of one.

LEMma 1: Upon observing $s_{b}$ and total demand d, the market maker sets the following prices:

$$
\left\{\begin{array}{l}
P=\pi_{b} X \text { if } d \leq 0 \\
P=\pi_{m} X \text { if } d>0
\end{array}\right.
$$

where

$$
\pi_{m}=\operatorname{Pr}(X \mid d>0)=\frac{1+e^{-\lambda \beta}+\mu\left(1-e^{-\lambda \beta}\right)}{2\left(1+e^{-\lambda \beta}\right)} .
$$

The blockholder exerts monitoring effort

$$
\mu=\frac{\beta X}{4 c}
$$

If and only if she observes signal $i_{b}, B$ sells

$$
\beta=\min \left(\frac{1}{\lambda}, \alpha\right)
$$

A full proof is in the Appendix; here I summarize the key intuition. If $d \leq 0$, the market maker knows that $B$ has sold and thus has received $i_{b}$. He therefore sets prices according to the posterior $\pi_{b}=\operatorname{Pr}\left(X \mid i_{b}\right)$ in equation (1). On the other hand, $d>0$ is consistent with both selling and not selling. In this case the market maker sets prices according to the posterior $\pi_{m}=\operatorname{Pr}(X \mid d>0)$ in equation (3). This gives rise to equation (2).

If $B$ receives signal $i_{b}$, she wishes to sell. As in Kyle (1985), in the absence of short-sale constraints, her optimal trade is finite $\left(\frac{1}{\lambda}\right)$ as she is concerned with excessive price impact. With short-sale constraints, $B$ is unable to sell more than $\alpha$, her initial holding. If $\alpha \leq \frac{1}{\lambda}$, then $\beta=\alpha$ : liquidity is sufficiently high that $B$ finds it optimal to sell her entire stake.

Lemma 2: The maximum sale volume $\beta$ is given by

$$
\beta=\alpha^{*}=\frac{\nu}{\nu+1}
$$

Blockholder effort $\mu$ is also maximized when $\alpha=\alpha^{*}$. Both $\beta$ and $\mu$ are increasing in $\alpha$ if $\alpha<\alpha^{*}$, and decreasing in $\alpha$ if $\alpha>\alpha^{*}$.

For $\alpha<\alpha^{*}$, a larger initial stake raises the amount that $B$ can sell upon negative information, and thus the incentives to become informed in the first place. Simply put, the benefits of information are higher as $B$ can make greater use of it. Empirical studies frequently assume that incentives to monitor and trade are increasing in block size. ${ }^{9}$ While intuitive, such a result

\footnotetext{
${ }^{9}$ For example, Boehmer and Kelley (2009) assume that "institutions could engage in information production
} 
is not delivered by standard models of informed trading with no constraints (e.g., Kyle (1985) and its variants). In these models, monitoring is independent of initial holdings: if an investor uncovers negative information about a stock she does not own, she can short sell. Similarly, in typical applications of the Kyle model to corporate finance (e.g., Maug (1998), Bolton and von Thadden (1998), Faure-Grimaud and Gromb (2004)), liquidity trades are discrete. Therefore, the informed party has to match liquidity traders' volumes to avoid being revealed, and so her orders are again independent of her initial stake. This paper generates a link between $\alpha$ and $\mu$ via the combination of continuous liquidity trader demand and short-sales constraints. It thus provides a theoretical framework underpinning the above empirical assumption. ${ }^{10}$

However, a second consequence of a higher stake is that it reduces liquidity. If $\alpha>\alpha^{*}$, liquidity is sufficiently low that $B$ chooses to sell only $\frac{1}{\lambda}$ if she receives signal $i_{b}$. Further increases in $\alpha$ reduce liquidity and thus the optimal trading volume $\frac{1}{\lambda}$; since $B$ expects to trade less on information, she has fewer incentives to gather information. The optimal block size to maximize information acquisition is therefore finite at $\alpha^{*}$.

If $B$ can short-sell at a cost (as is the case for hedge funds), it remains the case that increasing $\alpha$ from zero augments $\beta$ and $\mu$, as long as the cost is sufficiently nontrivial that the reduction in short-sale costs that results from raising $\alpha$ outweighs the negative effect on liquidity; the results are in the Internet Appendix. A higher initial stake increases the profits from selling on private information, since $B$ can costlessly unwind a long position rather than engage in costly short-sales. Hence, $B$ has greater incentives to acquire private information. As in the core model, once $\alpha$ is sufficiently large, further increases in $\alpha$ lower $\beta$ and $\mu$ because the negative effect on liquidity dominates, so the relationship is again concave.

Equity analysts are also potential monitors and can move prices without trading. The activity of equity analysts (and other hedge funds) is captured in the parameter $c$. This is $B$ 's cost of acquiring private information not already in the market and is therefore inversely related to the firm's information asymmetry. If analyst and hedge fund activity is high, most value-relevant information is already in the market price and the cost of acquiring incremental information is large. Section II demonstrates that this reduces the blockholder's value added.

It is straightforward to show that $B$ does not sell (hold) upon receiving $i_{g}\left(i_{b}\right)$. Selling in the absence of negative private information would drive the price down and reduce her portfolio value at $t=2$ as well as $t=3$. Hence, even a blockholder concerned with interim performance (e.g., a fund manager evaluated by investors) will not sell purely on public information.

once their holdings exceed a certain threshold." Rubin (2007) posits that "the probability that a particular institution will incur the costs to do so is higher if it enjoys a comparatively large ownership share."

${ }^{10}$ In Van Nieuwerburgh and Veldkamp (2008), monitoring does increase in the investor's holding, but because she is risk-averse and wishes to reduce uncertainty, rather than because a larger block expands the set of feasible trading strategies. 


\section{B. Market Efficiency}

This section analyzes the relationship between block size and price efficiency. A high-quality firm has a $\left(\frac{1}{2}+\frac{1}{2} \mu\right)$ chance of emitting signal $i_{g}$, in which case $B$ does not sell and the price is $\pi_{m} X$. It has a $\left(\frac{1}{2}-\frac{1}{2} \mu\right)$ chance of emitting signal $i_{b}$, in which case $B$ sells. If $u \leq \beta$ (which occurs with probability $1-e^{-\lambda \beta}$ ), then $d \leq 0$ and the price is $\pi_{b} X$. Otherwise the price is $\pi_{m} X$. Hence, the expected price of a high-quality firm is

$$
E[P \mid X]=X \pi_{X}
$$

where the expectation is taken over the possible realizations of $i$ and $u$, and

$$
\begin{aligned}
\pi_{X} & =\left[\frac{1}{2}+\frac{1}{2} \mu+\left(\frac{1}{2}-\frac{1}{2} \mu\right) e^{-\lambda \beta}\right] \pi_{m}+\left(\frac{1}{2}-\frac{1}{2} \mu\right)\left(1-e^{-\lambda \beta}\right) \pi_{b} \\
& =\frac{1}{2}\left(\mu^{2} \frac{1-e^{-\lambda \beta}}{1+e^{-\lambda \beta}}+1\right) .
\end{aligned}
$$

I use $\pi_{X}$ as a measure of market efficiency as it captures the closeness of expected prices to fundamental value. ${ }^{11}$ If $\pi_{X}=1$, price equals fundamental value and the market is fully efficient. As $\pi_{X}$ declines, the expected price of the high-quality firm falls from its fundamental value of $X$.

Proposition 1 (Market Efficiency): Market efficiency $\pi_{X}$ is maximized at $\alpha=\alpha^{*}$. It is increasing in $\alpha$ for $\alpha<\alpha^{*}$, and decreasing in $\alpha$ for $\alpha>\alpha^{*}$.

Proof: If $\alpha<\alpha^{*}$, then $\beta=\alpha$. Differentiating equation (7) with respect to $\alpha$ gives

$$
\frac{\partial \pi_{X}}{\partial \alpha}=\underbrace{\frac{\mu^{2} \lambda e^{-\lambda \alpha}}{\left(1+e^{-\lambda \alpha}\right)^{2}}}_{\text {trading effect }}+\underbrace{\frac{\mu^{2} \frac{\alpha \lambda}{1-\alpha} e^{-\lambda \alpha}}{\left(1+e^{-\lambda \alpha}\right)^{2}}}_{\text {camouflage effect }}+\underbrace{\mu \frac{1-e^{-\lambda \alpha}}{1+e^{-\lambda \alpha}} \frac{\partial \mu}{\partial \alpha}}_{\text {effort effect }} .
$$

The "trading effect" is the direct impact of $\alpha$. It is positive if and only if $\alpha<\alpha^{*}$, since an increase in $\alpha$ raises the amount sold by $B$ upon negative information. Simply put, if $B$ trades more, her trading (or non-trading) impounds more information into prices.

The "camouflage effect" operates indirectly through $\alpha$ decreasing liquidity. Since liquidity camouflages $B$ 's trades, this effect is positive for all levels of $\alpha$, as a fall in liquidity increases her effect on prices.

The "effort effect" operates indirectly through $\alpha$ affecting $\mu$. This effect is positive if and only if $\frac{\partial \mu}{\partial \alpha}>0$, that is, $\alpha<\alpha^{*}$. Increased effort leads to $B$ receiving a more informative signal. Her trades thus convey greater information about $V$. Overall, if $\alpha<\alpha^{*}$, all three effects are positive, and so an increase in $\alpha$ raises market efficiency.

\footnotetext{
${ }^{11}$ Note that the price is always efficient in the sense of equaling fundamental value conditional upon an information set. However, when $\alpha$ rises, this information set is richer and so prices are closer to (unconditional) fundamental value.
} 
If $\alpha>\alpha^{*}$, then $\beta=\frac{1}{\lambda}$. Differentiating with respect to $\alpha$ gives

$$
\frac{\partial \pi_{X}}{\partial \alpha}=\underbrace{\mu \frac{1-e^{-1}}{1+e^{-1}} \frac{\partial \mu}{\partial \alpha}}_{\text {effort effect }} .
$$

From Lemma 2, the trading effect is negative, as liquidity is sufficiently low that $B$ only sells $\frac{1}{\lambda}$, which is decreasing in $\alpha$. The negative trading effect exactly cancels out the positive camouflage effect. This leaves the effort effect, which is negative from Lemma 2. Q.E.D.

Even considering only the benefits of blockholders and ignoring their costs, the optimal block size for market efficiency is a finite level, $\alpha^{*}$. (Section II shows that the $\alpha$ that maximizes market efficiency also optimizes firm value). This result contrasts with some intervention models such as Shleifer and Vishny (1986), Maug (1998), and Kahn and Winton (1998) where firm value is monotonically increasing in block size. ${ }^{12}$ In this model, it is not block size per se that matters, but the associated optimal trading volume: prices are a function not of $\alpha$, but of $\min \left(\frac{1}{\lambda}, \alpha\right)$. A large block increases information revelation only to the extent that there is sufficient market liquidity to allow it to be sold entirely. Put differently, the fact that $B$ has not exited is less of a positive boost to the stock price if exit was difficult in the first place. This finite optimum is consistent with the finding that, while blockholders are common in the U.S. (Holderness (2009)), substantial blockholders are rare (La Porta, Lopez-de-Silanes, and Shleifer (1999)).

In reality, other market participants may be able to observe blockholders' sales with a lag, by studying Section 13 filings. This would strengthen $B$ 's impact on market efficiency. Since sales are only observed with a lag, B's profits from informed selling are unchanged. However, her price impact is greater: after the filing is made, the price moves even closer to fundamental value since the market can now observe the trade directly.

\section{Blockholders and Long-Term Investment}

The previous section links blockholders to increased financial market efficiency. This section demonstrates that the latter can in turn augment real efficiency, by addressing the potentially important myopia issue. I thus illustrate a social benefit for information gathering that is motivated purely by the private desire to profit from informed trading.

The model is extended to allow for managerial decisions. The risk-neutral ${ }^{13}$ manager $(M)$ places weight $\omega$ on the $t=2$ stock price and $1-\omega$ on the $t=3$ firm value, where $0<\omega<1$.

\footnotetext{
${ }^{12}$ Holmstrom and Tirole (1993) and Bolton and von Thadden (1998) also derive a non-monotonic effect of block size. In their models, market efficiency is maximized with a zero block. They derive finite optimal block sizes as they trade off market efficiency against, respectively, monitoring costs and intervention. In this paper, the optimal block size is finite even focusing on market efficiency alone. Burkart, Gromb, and Panunzi (1997) derive a finite optimal block size as too large a block can erode managerial initiative. In Pagano and Roell (1998), too large a block can lead to overmonitoring.

${ }^{13}$ Introducing managerial risk aversion would strengthen the results, since the blockholder reduces the variance in the price of a high-quality firm that emits $s_{b}$, as well as increasing its mean.
} 
Since this paper focuses on the solution to myopia rather than its cause, the concern with the current stock price $(\omega>0)$ is taken as exogenous. This is a standard assumption in the literature and can be motivated by a number of underlying factors, such as takeover threat (Stein (1988)), concern for managerial reputation (Narayanan (1985), Scharfstein and Stein (1990)), or the manager expecting to sell his own shares at $t=2$ (Stein (1989)). ${ }^{14}$

At $t=0$, the manager of a high-quality firm can invest in a long-term project that unambiguously increases fundamental value, but risks low interim earnings. The most natural example is intangible investment that is expensed and thus difficult to distinguish from losses made by a low-quality firm. Let $\theta \in[0,1]$ denote the amount of investment. Investment of $\theta$ boosts the firm's $t=3$ value to $V=X+g \theta$, but risks emitting $s_{b}$ at $t=1$ with probability $\theta^{2}$ (otherwise, $s_{g}$ is emitted). The parameter $g$ measures the productivity of the investment project. The choice of $\theta$ does not involve a personal utility cost to $M$ : there is no standard effort conflict. The availability of this investment project is not known to the market maker nor to $B$, to emphasize the fact that $B$ can induce $M$ to exploit growth opportunities even if she is unaware of their existence (in contrast with intervention models). In reality, new investment opportunities frequently become available to managers that were previously unforeseen. The Internet Appendix shows that the results continue to hold if $\theta$ is anticipated.

At $t=0$, the manager of a high-quality firm chooses $\theta$ to maximize

$$
(1-\omega)(X+g \theta)+\omega \theta^{2} \pi_{X} X+\omega\left(1-\theta^{2}\right) X
$$

The first term is firm value, multiplied by its weight in the objective function. The stock price is $X$ if $s_{g}$ is emitted, which occurs with probability $\left(1-\theta^{2}\right)$, else $\pi_{X} X$. This gives rise to the second and third terms.

LEMma 3: The manager chooses investment level $\theta$ given by

$$
\theta=\min \left(\frac{(1-\omega) g}{2 \omega X\left(1-\pi_{X}\right)}, 1\right)
$$

If $\theta<1$, it is increasing in $g$ and $\pi_{X}$, and decreasing in $X$ and $\omega$.

The amount of long-term investment is naturally increasing in its productivity $g$, and decreasing with the cost of emitting $s_{b}$. The latter is positively related to the difference in value between high- and low-quality firms $X$, and $M$ 's concern for the current stock price $\omega$. Note that myopia is rational: the stock price falls upon $s_{b}$ since it may have been emitted by a low-quality firm; given the risk of this decline, $M$ optimally sets $\theta$ below its first-best level of one.

Investment increases with $\pi_{X}$, since greater market efficiency means that prices more closely reflect fundamental value. Since $\pi_{X}$ in turn depends on $\alpha$, investment depends on block size.

\footnotetext{
${ }^{14}$ Even if the manager's sole objective is to maximize long-run shareholder value, he will care about the stock price as it affects the terms at which the firm can raise equity at $t=2$ (Stein (1996)).
} 
Indeed, taking first-order conditions of equation (11) with respect to $\alpha$ and calculating crosspartials with respect to $g, c$, and $\omega$ leads to Proposition 2 below, the main result of the paper.

Proposition 2 (Investment): Define $X_{1}=\frac{(1-\omega) g}{\omega}$ and $X_{2}=\frac{(1-\omega) g}{\omega} \frac{1+e^{-1}}{2 e^{-1}}$. For all $X$, investment $\theta$ is weakly increasing in $\pi_{X}$. It is therefore maximized at $\alpha=\alpha^{*}$, weakly increasing in $\alpha$ for $\alpha<\alpha^{*}$, and weakly decreasing in $\alpha$ if $\alpha>\alpha^{*}$. If $X \geq X_{2}$, these directional effects are strict and $\theta$ is uniquely maximized at $\alpha=\alpha^{*}$. If $X \leq X_{1}, M$ invests efficiently $(\theta=1)$ regardless of $\pi_{X}$ and thus $\alpha$.

The magnitude of the block-sensitivity of investment $\left|\frac{\partial \theta}{\partial \alpha}\right|$ is weakly increasing in $g$ and weakly decreasing in $c$ and $\omega$, that is, $\frac{\partial^{2} \theta}{\partial \alpha \partial g} \geq 0, \frac{\partial^{2} \theta}{\partial \alpha \partial c} \leq 0$, and $\frac{\partial^{2} \theta}{\partial \alpha \partial \omega} \leq 0$ for $\alpha<\alpha^{*}$ and $\frac{\partial^{2} \theta}{\partial \alpha \partial g} \leq 0$, $\frac{\partial^{2} \theta}{\partial \alpha \partial c} \geq 0$, and $\frac{\partial^{2} \theta}{\partial \alpha \partial \omega} \geq 0$ for $\alpha>\alpha^{*}$.

The central result of this paper is that blockholders can add value, even in the absence of an underlying effort conflict and the ability to intervene. By engaging in informed trading to maximize their own speculative profit, they can promote long-term investment. For $\alpha<\alpha^{*}$, increasing block size raises market efficiency $\pi_{X}$ (Proposition 1) and thus makes the price more closely reflect fundamental value. From equation (11), a higher $\pi_{X}$ in turn augments real efficiency: the manager is more willing to undertake positive-NPV long-term investment projects that risk interim turbulence because the stock price fall upon short-term losses is attenuated.

While Proposition 2 shows that sizable shareholders promote investment, the corollary is that a key cost of dispersed ownership is that it magnifies myopia. This cost contrasts with the shirking traditionally focused upon (e.g., Roe (1994)) and has different policy implications. If effort is the main problem, equity compensation and a more active takeover market are potential solutions. However, if myopia is the principal issue, such measures make it worse.

The beneficial effect of a blockholder on investment, $\frac{\partial \theta}{\partial \alpha}$, is decreasing in $c$ and thus increasing in information asymmetry. Where information asymmetry is high, there is more information for $B$ to impound into prices and so she has a greater incremental effect. The blockholder's impact is also increasing in the profitability of investment $g$ up to a point $\left(\frac{\partial^{2} \theta}{\partial \alpha \partial g}>0\right)$ : if the investment is unattractive, it will be little exploited even if $B$ makes prices relatively efficient. However, if $g$ is sufficiently high that $X \leq X_{1}, \theta=1 \forall \alpha$ and $\frac{\partial \theta}{\partial \alpha}=0$ : the investment opportunity is sufficiently attractive that $M$ pursues it fully even in the absence of a blockholder. In a similar vein, the impact of higher block size is greatest for moderate levels of $\omega$. If $M$ is greatly concerned with interim performance, he will still underinvest even in the presence of a blockholder $\left(\frac{\partial^{2} \theta}{\partial \alpha \partial \omega}<0\right)$. On the other hand, if the stock price is a minor concern $\left(X \leq X_{1}\right), M$ invests efficiently in the first place.

\section{A. Does Liquidity Deter Investment?}

The previous section studies the optimal $\alpha$ for firm value, holding liquidity constant. This section now examines the effect of liquidity $\nu$ on investment. I first assume that $\alpha$ is exogenous 
and show that increasing $\nu$ boosts investment at low levels, but reduces it at high levels. Next, I allow $\alpha$ to be endogenously chosen by the blockholder in response to liquidity, in order to maximize her total payoff. In this case, increasing $\nu$ always boosts investment.

\section{A.1. Exogenous Block Size}

Proposition 3 (Liquidity, Exogenous Block Size): Holding a constant, market efficiency and investment are maximized at $\nu^{*}=\frac{\alpha}{1-\alpha}$. They are increasing (decreasing) in $\nu$ for $\nu<(>) \nu^{*}$.

From Proposition 2, investment is increasing in market efficiency. Market efficiency in turn depends on two factors: how much information $B$ gathers, and the extent to which this information is incorporated into prices. While liquidity increases information gathering by augmenting trading profits, it also camouflages $B$ 's trades and reduces their price impact. For low (high) levels of efficiency, the first (second) effect dominates. If there is zero liquidity, $B$ does not trade or monitor; if liquidity is infinite, she does not affect prices. The non-monotonic effect of liquidity contrasts with previous papers such as Holmstrom and Tirole (1993) and Faure-Grimaud and Gromb (2004), where augmenting liquidity always increases stock price informativeness. There is no camouflage effect in those papers as the informed investor's trades are unbounded; here, $B$ 's maximum sale is capped at $\alpha$ due to short-sales constraints. ${ }^{15}$

As summarized by Bhide (1993), liquidity is undesirable in most previous papers, where block size is exogenous and the blockholder chooses between intervention and intentional exit. ${ }^{16}$ In such papers, the blockholder adds value through voice; since voice and exit are mutually exclusive, liquidity hinders the former by facilitating the latter. Here, the blockholder adds value through retaining her stake through interim turbulence, increasing investment ex ante. Since loyalty and exit are similarly mutually exclusive, it might seem that liquidity is again undesirable as it encourages exit and thus deters loyalty. This is indeed the conventional wisdom: liquidity allows shareholders to sell upon weak earnings, and thus makes managers even more concerned with earnings. A number of commentators (e.g., Porter (1992), Thurow (1993)) argue that the U.S.'s liquid capital markets hinder long-term investment, and hence have called for policy intervention to reduce liquidity.

This paper shows that, even holding $\alpha$ exogenous, increasing liquidity from low levels can promote investment, and thus has very different policy implications. Although loyalty and exit are indeed mutually exclusive, this leads to complementarities between them. The power of loyalty relies on the threat of exit. By making exit more feasible, increased liquidity renders

\footnotetext{
${ }^{15}$ Some previous blockholder models (where $\alpha$ is not chosen by $B$ ) also conclude liquidity is not unambiguously desirable. In Kahn and Winton (1998), liquidity has no effect, rather than a non-monotonic effect. Bolton and von Thadden (1998) do feature an optimal level of liquidity. This arises because greater liquidity means a lower stake: in their paper, liquidity is $(1-\alpha)$, so higher liquidity can only be achieved by a lower $\alpha$, which reduces intervention and thus firm value. In this paper, liquidity is $\nu(1-\alpha)$, where $\nu$ captures factors that affect liquidity unrelated to free float. The model shows that there is an optimal $\nu$, even if $\alpha$ is constant.

${ }^{16}$ Faure-Grimaud and Gromb (2004) demonstrate that liquidity encourages intervention as it allows the stock price to reflect these value gains and thus the blockholder to earn a return if she has to exit unexpectedly, due to a liquidity shock. In their model, exit is not intentional.
} 
loyalty more meaningful. In this model, the blockholder does not promote investment simply by being a "long-term" investor who never sells; by contrast it is the possibility of selling in the short-run that encourages the manager to make long-term decisions. Indeed, if market illiquidity compelled the blockholder always to hold for the long run, she has no effect on stock prices and investment. The fact that she has not sold upon bad news is uninformative if she was unable to sell in the first place.

This result marks an important distinction from intervention models. If the blockholder has no control rights, allowing her to sell in the short term is beneficial for firm value as it can promote investment. By contrast, if the blockholder is interventionist, the possibility of shortterm selling may induce her to step in and force the manager to undertake myopic decisions. Therefore, not only is it unnecessary for blockholders to have control rights in order to exert governance, but it may also be undesirable: to the extent that blockholders have short-term considerations, they may add more value to the firm if they lack control rights.

A short-term blockholder without control rights might try to induce myopia by threatening to punish the manager by selling her stake if earnings are low (because of investment). However, such a threat is not credible as it is dynamically inconsistent: once the firm announces low earnings, they are immediately incorporated into the stock price, and so the blockholder cannot profit by selling. Opponents of liquidity argue that it allows shareholders to sell upon interim losses, but this view lacks a theoretical framework to explain why investors would sell upon weak earnings. In an efficient market, the stock price reacts immediately to public information such as low earnings, removing the incentive to exit. Investors can only profit by trading on private information, and so trading is desirable as it impounds such information into the stock price - particularly if the trader has a sizable stake and so is likely to have engaged in fundamental analysis. Indeed, Yan and Zhang (2009) show empirically that investors who trade frequently are better informed than those who rarely trade. Moreover, the stocks that they own do not exhibit long-run reversals, which is inconsistent with the view that they encourage shorttermism. The frequent trading observed in the U.S. may thus be a positive sign, as it suggests that information is being impounded into prices.

\section{A.2. Endogenous Block Size}

Thus far, the analysis has focused on the normative issue of the block size that maximizes firm value, $\alpha^{*}$. I now turn to the positive question of which block size is most likely to be observed empirically. While the firm may be able to influence $\alpha$ temporarily (e.g., by privately placing equity with a blockholder), $B$ can trade away from this initial stake. The only initial block size that is robust to re-trade is the private optimum, $\alpha_{P}^{*}$, that maximizes $B$ 's trading profits net of monitoring costs. This would also be the block size that $B$ would choose if she bought shares at $t=0$ and her purchase was unobserved. ${ }^{17}$ (After the purchase, $\alpha$ becomes

\footnotetext{
${ }^{17}$ In Kyle and Vila (1991), the blockholder camouflages her purchase by trading with liquidity investors. In their model, this leads to an additional benefit of liquidity - it facilitates initial block acquisition.
} 
publicly known through Section 13 filings.)

I now characterize this private optimum. If $B$ owns $\alpha$, her expected gross trading profits are given by

$$
\Theta(\alpha)=\operatorname{Pr}\left(s_{b}\right) \frac{1}{2} \beta e^{-\lambda \beta} X\left(\pi_{m}-\pi_{b}\right) .
$$

The first term is the probability that $s_{b}$ is emitted ${ }^{18}$ and the second is the probability that $B$ receives signal $i_{b}$, in which case she sells $\beta$. With probability $e^{-\lambda \beta}, u>\beta$ and so $B$ 's information is not revealed to the market; she earns $X\left(\pi_{m}-\pi_{b}\right)$ per unit. Her expected monitoring costs are given by

$$
\Psi(\alpha)=\operatorname{Pr}\left(s_{b}\right) \frac{\beta^{2} X^{2}}{32 c}
$$

and so her objective function is

$$
\Theta(\alpha)-\Psi(\alpha)=\frac{\operatorname{Pr}\left(s_{b}\right) X^{2}}{8 c} \beta^{2}\left(\frac{e^{-\lambda \beta}}{1+e^{-\lambda \beta}}-\frac{1}{4}\right) .
$$

Proposition 4 below states that both $\alpha_{P}^{*}$ and $\theta$ are monotonically increasing in $\nu$.

Proposition 4 (Liquidity, Endogenous Block Size): The privately optimal block size $\alpha_{P}^{*}$ is strictly less than the firm value optimum $\alpha^{*}$, and monotonically increasing in liquidity $\nu$. Allowing for the endogeneity of block size, investment $\theta$ is monotonically increasing in $\nu$.

Two forces reduce $\alpha_{P}^{*}$ below $\alpha^{*}$. First, a larger block size augments monitoring costs, which the blockholder bears but are absent from the firm's objective function. Second, a larger block reduces liquidity and thus trading profits, which are also absent from the firm's objective function. By contrast, a decrease in liquidity has a direct positive effect on firm value through the camouflage effect.

When $\alpha$ is exogenous, investment is concave in liquidity: too high liquidity camouflages $B$ 's trade, which is capped at $\alpha$. When $\alpha$ is endogenous, the camouflage effect is attenuated since $\alpha$ rises with liquidity - higher $\nu$ allows $B$ to trade more, and thus she chooses a higher block. Hence, investment is now monotonically increasing in liquidity. This result echoes Maug (1998), who also shows that liquidity is always desirable when $\alpha$ is endogenous. However, our results for exogenous $\alpha$ are different. In Maug (1998), if $\alpha$ is exogenously high ${ }^{19}$, augmenting liquidity reduces firm value (even if liquidity is currently low), and so the benefits of liquidity operate entirely through its effect on initial block formation. In this paper, increasing liquidity from low levels (if $\nu<\frac{\alpha}{1-\alpha}$ ) unambiguously increases firm value, even if $\alpha$ is exogenous.

In sum, there are two effects of greater liquidity. First, as Maug (1998) shows, it leads to

\footnotetext{
${ }^{18}$ If $q$ is the proportion of high-quality firms in the economy and $r$ is the probability that a high-quality firm emits $s_{b}$, then $\operatorname{Pr}\left(s_{b}\right)=1-q+q r$. Since $\operatorname{Pr}\left(X \mid s_{b}\right)=\frac{q r}{1-q+q r}=\frac{1}{2}, r=\frac{1-q}{q}$ and so $\operatorname{Pr}\left(s_{b}\right)=2-2 q$.

${ }^{19}$ In Maug (1998), liquidity is undesirable if a is exogenous and exceeds $c_{M} /(H-L)$, where $c_{M}$ is the cost of intervention, and $H-L$ is the gain in firm value from intervening. This condition is independent of liquidity, and so if a is sufficiently high, raising liquidity can be harmful even if it is initially low. In this paper, raising liquidity from low levels is always beneficial.
} 
larger blocks. Second, it induces increased liquid trading by these blocks. In Maug's model, when $\alpha$ is exogenously high and so liquidity only leads to liquid trading, increasing $\nu$ is undesirable because it deters blockholder intervention. By contrast, as discussed in Section II.A.1, in this paper liquid trading alone can be beneficial. Hence, liquidity has benefits other than its positive effect on initial block size first shown by Maug. The key to this result is that liquid trading is the very mechanism through which the blockholder adds value, and so it is not achieved in intervention models.

The result that liquidity can be desirable even when $\alpha$ is exogenous is potentially important, because legal or institutional factors may deter $B$ from endogenously changing $\alpha$ in response to greater liquidity, and thus the first benefit from being obtained (see, for example, Roe (1994)). For example, certain shareholders choose to hold fewer than $5 \%$ of a firm's shares to avoid triggering a Section 13(d) filing, or hold fewer than 10\% to avoid being classified as an insider. In the U.S., ownership is fragmented despite high liquidity, suggesting that these forces may be important. This paper shows that liquidity can be desirable even if it does not lead to Maug's advantage of more concentrated ownership.

\section{B. Further Applications}

In the general model, $\theta$ is any action that boosts fundamental value but risks emitting $s_{b}$. Thus far, $\theta$ has been interpreted as intangible investment and $s_{b}$ as short-term losses, but there are many additional applications. Signal $s_{b}$ is any observable characteristic that reduces outsiders' assessment of firm value since it is also consistent with a low-quality firm. Therefore, $\theta$ can represent fully observable investment for which the motive or quality is unknown. The fundamental problem with investment is that the associated expenditures are difficult to interpret, even if they are fully visible. While R\&D can be reported separately on the income statement and atomistic shareholders can costlessly observe it, they do not know whether a rise in $R \& D$ results from managerial excess (bad news about agency costs), the need to compensate for failed past R\&D efforts (bad news about operating costs), or efficient exploitation of new growth opportunities (good news). Upon observing significant investment for which the motive is unclear, $B$ will gather information and trade accordingly.

Low $\theta$ can also represent the pursuit of myopic actions that temporarily boost outsiders' perceptions, such as accounting manipulation, fraud, or "milking" customer reputation through lowering product or service quality. Johnson, Ryan, and Tian (2009) document a significant correlation between corporate fraud and unrestricted stock compensation, and Peng and Roell (2008) find that vested options encourage executives to manipulate earnings. Since the manager can sell unrestricted stock and exercise vested options immediately, such compensation increases $\omega$ and thus reduces $\theta$. Allowing the manager of a low-quality firm to undertake a value-destructive action that gives a probability of yielding $s_{g}$ (so that $s_{g}$ is also imperfectly informative) would reinforce the results of the core model. The presence of a blockholder reduces the manager's ability to deceive the market about his firm's quality, even in the short run. 


\section{Empirical Implications}

This paper's broad objective is to demonstrate that blockholders can add value even if they are unable to intervene, which potentially explains the prevalence of small blockholders in the U.S. While the model also generates a number of more specific empirical implications, it must be stressed that there are significant challenges in testing them. First, the key variable (block size) is endogenous, as shown in Section II.A.2. Therefore, it is insufficient simply to document significant correlations between block size and an outcome variable. To show that blockholders have the effects predicted in the model, it is necessary to identify sources of exogenous variation in block size. Second, empirical tests will need to take into account the model's specific setting, for example, exclude inside blockholders and blockholders who rarely trade on information (such as families or index funds), and focus on situations where short-sales costs are nontrivial.

The implications are divided into three broad themes: the effect of blockholders on financial markets, on firm behavior, and on firm value. We commence with the first category. In this model, blockholders exert governance through being informed traders, which in turn leads to four predictions - they have superior information; their trades impound information into market prices; they earn trading profits; and their presence increases market efficiency. Moreover, the magnitude of these effects should be concave in block size. These predictions are unique to a framework where blockholders add value through trading, rather than intervention, and where information acquisition depends endogenously on block size. In standard models of informed trading (e.g., Kyle (1985)), block size has no effect on information acquisition incentives. Blockholders thus generate no excess returns, and their sales are no more informative than any other investor's trades. Owing to the short-sales constraint introduced by this paper, private information is increasing in block size (up to a point). Bushee and Goodman (2007) find that the private information content of an institutional investor's trade is indeed increasing in her stake, and Heflin and Shaw (2000) and Rubin (2007) document that ownership concentration depresses liquidity as other market participants fear informed trading losses. More generally, the paper suggests that ownership concentration may be a more accurate measure of investor informedness than total institutional ownership. The latter plausibly measures the potential to obtain information (since institutions have the expertise to conduct fundamental analysis), but concentrated stakes are necessary to incentivize them to undertake such analysis. If institutional ownership is high but dispersed, shareholders may not bear the costs of monitoring.

The second prediction is that, owing to blockholders' superior information, their sales should convey negative news and depress the stock price (unless these sales are motivated by noninformational reasons, considered later). Scholes (1972) and Mikkelson and Partch (1985) show that the negative stock price reaction to secondary block distributions is due to information, rather than a sudden increase in supply or a reduction in expected blockholder monitoring. Mikkelson and Partch (1985) further find that the negative price impact is increasing in the size of the block sold but not the blockholders' initial stake. This result supports the model's 
prediction that it is the amount traded that matters, not $\alpha$ per se. ${ }^{20}$ Sias, Starks, and Titman (2006) show that the positive correlation between institutional ownership changes and stock returns is causal, rather than institutions predicting future returns, or following short-term momentum strategies and responding to past returns. Moreover, they demonstrate that the price changes result from information, rather than liquidity or supply effects. All of these papers therefore provide additional support for the first prediction, that blockholders have superior information.

Although blockholders move prices, the third prediction is that they still earn trading profits as the stock price is only partially revealing. Indeed, Parrino, Sias and Starks (2003) show that blockholders sell in advance of forced CEO turnover (a sign of low fundamental value), and that long-horizon returns are negative after such sales. Institutions with larger positions sell to a greater degree, implying they are better informed. Chen, Harford, and Li (2007) find that large shareholders sell in advance of value-destructive mergers. Gallagher, Gardner, and Swan (2008) demonstrate that frequent trading by blockholders is profitable. Again, these papers also provide support for the first prediction of superior information.

The fourth prediction stems is generated by Proposition 1, which predicts that price efficiency is concave in block size. Unlike the second prediction, this implication concerns the mere presence of blockholders rather than their actual trades. Brockman and Yan (2009) find that stocks with higher block ownership contain greater firm-specific information, as evidenced by a higher probability of informed trading, higher idiosyncratic volatility, and low synchronicity with the market. Also consistent with the model, these effects do not exist for blockholders who are employee share ownership plans (ESOPs), which likely do not trade on information. Amihud and $\mathrm{Li}$ (2006) find that the price reaction to dividends is decreasing in institutional ownership (which is typically highly correlated with blockholdings); their interpretation is that institutional investors have already gathered and traded upon the information that would be conveyed by the dividend change. Event-drift is another measure of price efficiency: Bartov, Radhakrishnan, and Krinsky (2000) find that post-earnings announcement drift is lower in the presence of greater institutional ownership, which is consistent with the view that institutions impound earnings information faster into prices. Such correlations need not imply causation; inefficient prices could attract blockholders as the potential for trading profits is higher. Boehmer and Kelley (2009) document a causal positive relationship between institutional ownership and price efficiency. Both institutional trading and the level of institutional holdings (in the absence of trading) are associated with efficiency. This result is consistent with the model, since blockholders can increase price efficiency either by trading on bad news, or not trading on good news.

The second category of predictions concerns the effect of blockholders on firm behavior, and are more challenging to test. Proposition 2 predicts that investment is concave in block size.

\footnotetext{
${ }^{20}$ Block size per se would matter if blockholders' superior information arises because their control rights grant them preferential access to information. In this paper, superior information arises from greater incentives to gather it.
} 
The primary interpretation of $\theta$ is intangible investment, which presents empirical difficulties. Blockholders are particularly valuable in promoting unobservable investment, but such investment will also be invisible to the empiricist. A potential indirect measure is Tobin's $q$, which measures the capitalized value of growth opportunities. Moreover, as explained in Section II.B, $\theta$ can also represent observable investment. While the total quantity of R\&D and capex can be verifiably communicated in financial statements, its quality cannot be. Although CEOs can disclose the amount of investment, they still perceive strong disincentives to invest (Graham, Harvey, and Rajgopal (2005)), since atomistic shareholders cannot distinguish productive investment from wasteful expenditure. Even if the productivity of investment is observable, it may not be incorporated by the market if it is intangible, as shown by Edmans (2009). Indeed, Lee and O'Neill (2003) and Baysinger, Kosnik, and Turk (1991) find a positive correlation between ownership concentration and $R \& D$. While $R \& D$ is an input measure, patents are an output measure and thus more closely related to the quality of investment. Lee (2005) finds a positive correlation between ownership concentration and patents in the U.S. Atanassov (2008) shows that blockholders reduce the negative impact of antitakeover legislation on patent citations. ${ }^{21}$

However, $\alpha$ is endogenous and may itself be determined by $\mathrm{R} \& \mathrm{D}$, or a third unobservable variable may have a causal effect on both variables. For example, a firm with high R\&D may also have significant uncertainty, increasing the potential for informed trading profits and attracting blockholders. Thus, the above cross-sectional correlations can only be interpreted as tentative support for the model. Since the empirically chosen $\alpha$ is likely to be the one chosen by the blockholder, appropriate instruments will be those that shift the private optimum but are unrelated to R\&D. Examples include a negative liquidity shock, a sudden increase in surplus cash (from the sale of other holdings or investor inflows), temporary stock underpricing, a change in management at the blockholder, or a change in regulation. Cronqvist and Fahlenbrach (2009) use a time-series approach, tracking the effect of changes in block ownership within a firm. They find that the appearance of certain blockholders in a corporation subsequently leads to a significant increase in investment. One potential argument against their causal interpretation is that blockholders face substantial barriers to intervention (as stated in the introduction), rendering it difficult for them to actively change investment policy. This paper shows that causation is possible without intervention: the arrival of the blockholder allows the manager to pursue investment projects that he previously avoided owing to fears of interim turbulence. Becker, Cronqvist and Fahlenbrach (2008) use the density of wealthy individuals near a firm's headquarters as a geographic instrument to identify $\alpha$.

Section II.B notes that low $\theta$ can also be interpreted as the pursuit of actions that reduce value but improve investors' short-term perceptions of the firm, such as accounting manipulation. Blockholders will "see through" such actions and thus deter them. Burns, Kedia, and Lipson (2008) find that ownership concentration is correlated with fewer and less severe financial

\footnotetext{
${ }^{21}$ Hansen and Hill (1991), Bushee (1998), and Wahal and McConnell (2000) show a positive association between R\&D and institutional ownership; the latter is typically highly correlated with blockholdings. Bushee also finds that myopia is driven by momentum investors who trade on current earnings and have small holdings.
} 
restatements. By contrast, diversified institutions are positively associated with restatements, likely because they trade on public earnings rather than study fundamental value. Dechow, Sloan, and Sweeney (1996) and Farber (2005) find that firms identified by the SEC as fraudulently manipulating earnings have lower blockholdings. Again, such cross-sectional correlations can only be interpreted as weak support of the model since earnings manipulation may deter blockholders. A definitive test of this prediction requires an instrument for block size.

Finally, I turn to the predicted relationship between block size and firm value. If block size is always at the firm value optimum, there should be no relationship (as noted by Demsetz and Lehn (1985) in the context of managerial ownership and firm value). However, as discussed earlier, the empirically observed block size will likely differ from the firm value optimum, thus generating the cross-sectional prediction that firm value is concave in the stake held by an outside blockholder. While other papers show that too large a block can be inefficient, in most of these papers the inefficiencies arise from the loss of private benefits (Pagano and Roell (1998)) or underdiversification, which do not affect the stock price. Therefore, these papers would not generate this prediction. However, Burkart, Gromb, and Panunzi (1997) do share the prediction that market value is concave in block size, since too large a block reduces managerial initiative.

The time-series analog of the above prediction is that unanticipated block increases (decreases) in block size should generate positive (negative) event study reactions when initial block size is low, but the effects are reversed when initial block size is high. Changes in block size may represent exogenous changes to the private optimum (e.g., liquidity shocks), which move it closer to or further from the firm value optimum. Moreover, the absolute magnitude of these changes should be increasing in information asymmetry and concave in growth opportunities. Models where firm value is monotonically increasing in block size would predict that increases in block size would always have a positive effect.

Testing this prediction requires identifying changes in block size not motivated by information. (As noted earlier, information-based trades should move prices in the same direction as the order, regardless of initial block size.) Wruck (1989) therefore focuses on private sales of equity: since the purchaser is buying a large stake, he will undertake extensive due diligence to ensure he is not trading against unreleased information. She finds that increases in ownership concentration lead to increases (decreases) in firm value for low (moderate) levels of initial concentration, consistent with this paper (and also with Burkart, Gromb, and Panunzi (1997)).

\section{Conclusion}

The traditional view of corporate governance is that it is exerted through direct intervention in a firm's operations. Under such a view, concentrated shareholders are desirable as they have both the incentives and control rights to intervene. However, the dominant shareholding structure in the U.S. is one of small blockholders. Compounded with substantial legal and institutional impediments to intervention, it might appear that U.S. firms are poorly governed 
and their blockholders play a limited role.

This paper offers a different perspective. It shows that blockholders can significantly enhance firm value even if they lack control rights. By gathering and trading on intangible information, they cause prices to reflect fundamental value rather than current earnings. This can encourage managers to undertake long-term investment - arguably the primary challenge facing the modern firm.

In the 1980s and early 1990s, many commentators predicted that the U.S. economy would be surpassed by Japan, particularly in R\&D-intensive industries, arguing that the U.S.'s liquid capital markets are a deterrent to investment. This paper shows that short-term trading may in fact support long-term investment, as it impounds its effects into stock prices. Thus, the U.S. capital allocation system may be significantly more investment-friendly than widely believed, potentially explaining why the above fears have not materialized.

While the core model focuses on the effect of blockholders on myopia, the trading mechanism in the paper can attenuate many other agency problems, such as shirking (see, for example, Admati and Pfleiderer (2009) and Edmans and Manso (2009)). The model can thus reconcile evidence on blockholders' low ability to intervene (Black (1990), La Porta, Lopez-de-Silanes, and Shleifer (1999), and Becht et al. (2009)) with studies that show that blockholders affect corporate decisions. $^{22}$ The model can also be extended to demonstrate how any agent that gathers information about fundamental value and impounds it into prices can improve managers' ex ante decisions and thus real efficiency. This implies a social benefit of short-sellers (such as hedge funds) and equity analysts, although these actors also reduce the incremental role for blockholders.

More generally, this paper suggests a new way of thinking about the governance role of blockholders, giving rise to a number of potential avenues for future research. Existing theories have modeled blockholders as controlling entities who add value through intervention, and accordingly most empirical studies have focused on private benefits and control rights. By contrast, the model indicates that blockholders can be perceived as informed traders who exert governance through influencing prices. Therefore, future corporate finance theories of blockholders could import more complex effects typically featured in asset pricing models of informed trading. For example, Edmans and Manso (2008) show that splitting a stake between multiple informed traders increases trading volumes, market efficiency, and consequently firm value. They therefore derive multiple blockholders as an optimal shareholding structure, consistent with empirical evidence. Similarly, new empirical directions may arise from perceiving blockholders as informed traders rather than controlling entities. They should therefore generate trading profits and augment price efficiency, and their value added should depend on liquidity.

\footnotetext{
${ }^{22}$ See, for example, Chen, Harford, and Li (2007) on the beneficial effect of institutions on M\&A decisions, and Cronqvist and Fahlenbrach (2009) on their influence of corporate policies in general. Chen et al. show this benefit is increasing in block size and the absence of business ties (which is related to the threat of exit).
} 


\section{Appendix}

Proof of Lemma 1: Let $\widehat{\beta}$ denote the market maker's conjecture about the amount sold by $B$ upon receiving $i_{b}$, and $\widehat{\mu}$ denote the conjectured monitoring effort. If $d \leq 0$, the market maker knows that $B$ has sold, and thus received $i_{b}$. If $d>0$, the posterior probability that $i_{g}$ was received is

$$
\operatorname{Pr}\left(i_{g} \mid d>0\right)=\frac{\lambda e^{-\lambda d} \operatorname{Pr}\left(i_{g}\right)}{\lambda e^{-\lambda d} \operatorname{Pr}\left(i_{g}\right)+\lambda e^{-\lambda(d+\widehat{\beta})} \operatorname{Pr}\left(i_{b}\right)} .
$$

Using $\operatorname{Pr}(X \mid d>0)=\operatorname{Pr}\left(X \mid i_{g}\right) \operatorname{Pr}\left(i_{g} \mid d>0\right)+\operatorname{Pr}\left(X \mid i_{b}\right) \operatorname{Pr}\left(i_{b} \mid d>0\right)$, we eventually obtain

$$
\operatorname{Pr}(X \mid d>0)=\frac{1+e^{-\lambda \widehat{\beta}}+\widehat{\mu}\left(1-e^{-\lambda \widehat{\beta}}\right)}{2\left(1+e^{-\lambda \widehat{\beta}}\right)} .
$$

Hence, the market maker sets the following prices:

$$
\left\{\begin{array}{l}
P=\frac{1-\widehat{\mu}}{2} X \text { if } d \leq 0 \\
P=\frac{1+e^{-\lambda \widehat{\beta}}+\widehat{\mu}\left(1-e^{-\lambda \widehat{\beta}}\right)}{2\left(1+e^{-\lambda \widehat{\beta}}\right)} X \text { if } d>0 .
\end{array}\right.
$$

If $B$ has received $i_{b}$, the firm is worth $P=\frac{1-\mu}{2} X$ to her. Since the market maker's conjecture is correct in equilibrium, $\widehat{\mu}=\mu$ and so $B$ makes zero profit if $d \leq 0$. She only makes a profit if $d>0$, that is, $u>\beta$. Her objective function is therefore

$$
\max _{\beta \leq \alpha} \beta X \int_{\beta}^{\alpha}\left[\frac{1+e^{-\lambda \widehat{\beta}}+\widehat{\mu}\left(1-e^{-\lambda \widehat{\beta}}\right)}{2\left(1+e^{-\lambda \widehat{\beta}}\right)}-\frac{1-\mu}{2}\right] \lambda e^{-\lambda u} d u
$$

The optimum is given by

$$
\beta=\left\{\begin{array}{l}
\alpha \text { if } \alpha \leq \frac{1}{\lambda} \\
\frac{1}{\lambda} \text { if } \alpha>\frac{1}{\lambda}
\end{array}\right.
$$

as in equation (5). Since the market maker's belief is correct in equilibrium, $\widehat{\beta}=\beta$. This gives rise to equations (2) and (3).

Now consider $B$ 's monitoring decision. Net of monitoring costs, $B$ 's profits are given by

$$
\begin{aligned}
& \operatorname{Pr}\left(i_{b}\right) \beta\left[\operatorname{Pr}(u>\beta)(P \mid d>0)+\operatorname{Pr}(u \leq \beta)(P \mid d \leq 0)-E\left[V \mid i_{b}\right]\right]-\frac{1}{2} c \mu^{2} \\
& =\frac{1}{2} \beta X\left[e^{-\lambda \beta} \frac{1+e^{-\lambda \beta}+\widehat{\mu}\left(1-e^{-\lambda \beta}\right)}{2\left(1+e^{-\lambda \beta}\right)}+\left(1-e^{-\lambda \beta}\right) \frac{1-\widehat{\mu}}{2}-\frac{1-\mu}{2}\right]-\frac{1}{2} c \mu^{2},
\end{aligned}
$$

where the first $\frac{1}{2}$ is the probability that $i_{b}$ is received and $e^{-\lambda \beta}$ is the probability that $u>\beta$. 
Differentiating with respect to $\mu$ and then setting $\widehat{\mu}=\mu$ derives the optimal $\mu$ as

$$
\mu=\frac{\beta X}{4 c}
$$

Q.E.D.

Proof of Lemma 2: The blockholder's trade is

$$
\beta=\min (\nu(1-\alpha), \alpha)
$$

This is maximized at $\nu(1-\alpha)=\alpha$, that is, $\alpha=\frac{\nu}{\nu+1}$. Since $\alpha=\frac{\nu}{\nu+1}$ maximizes $\beta$, it also maximizes $\mu=\frac{\beta X}{4 c}$. Q.E.D.

Proof of Lemma 3: Taking first-order conditions of equation (10) with respect to $\theta$ yields

$$
(1-\omega) g-2 \omega \theta X\left(1-\pi_{X}\right)
$$

The first term represents the increase in $V$ that results from increased investment, and the second term captures the lower expected stock price that results from the increased probability of emitting $s_{b}$. Setting the first-order condition to zero and imposing the constraint $\theta \leq 1$ leads to equation (11). The comparative statics with respect to $g, \pi_{X}, X$, and $\omega$ follow immediately. Q.E.D.

Proof of Proposition 2: From equation (11), $\theta=1$ if $\frac{(1-\omega) g}{2 \omega X\left(1-\pi_{X}\right)} \geq 1$, that is,

$$
X \leq \frac{(1-\omega) g}{2 \omega\left(1-\pi_{X}\right)}
$$

In turn, the minimum value of $\pi_{X}=\frac{1}{2}\left(\mu^{2} \frac{1-e^{-\lambda \beta}}{1+e^{-\lambda \beta}}+1\right)$ is $\frac{1}{2}$ (when $\alpha=0$ ) and the maximum value is $\frac{1}{1+e^{-1}}$ (when $\nu=1, \alpha=\frac{1}{2}$ and $X=8 c$ so $\mu=1$ ). Hence, when $X \leq X_{1}, \theta=1$ regardless of the value of $\pi_{X}$ and thus $\alpha$. Conversely, when $X>X_{2}, \theta<1 \forall \alpha$. Differentiating (11) with respect to $\alpha$ yields

$$
\begin{aligned}
\frac{\partial \theta}{\partial \alpha} & =\frac{\partial \theta}{\partial \pi_{X}} \frac{\partial \pi_{X}}{\partial \alpha} \\
& =\frac{(1-\omega) g}{2 \omega X\left(1-\pi_{X}\right)^{2}} \frac{\partial \pi_{X}}{\partial \alpha}
\end{aligned}
$$

Hence, when $X>X_{2}, \theta$ is strictly increasing in $\pi_{X}$ and $\frac{\partial \theta}{\partial \alpha}$ has the same sign as $\frac{\partial \pi_{X}}{\partial \alpha}$. From Proposition $1, \theta$ is therefore strictly increasing (decreasing) in $\alpha$ if $\alpha<(>) \alpha^{*}$. For $X=X_{2}$, $\theta=1$ for at most one value of $\alpha\left(\alpha=\alpha^{*}\right)$, and so the directional relationships remain strict. For $X_{1}<X<X_{2}, \theta$ may be 1 for a continuum of values of $\alpha$, and so the relationship between $\theta$ and $\pi_{X}$ (and thus $\alpha$ ) is no longer strict. 
If $\frac{\partial \theta}{\partial \alpha} \neq 0$, the cross-partials $\frac{\partial^{2} \theta}{\partial \alpha \partial g}$ and $\frac{\partial^{2} \theta}{\partial \alpha \partial \omega}$ are given by

$$
\begin{aligned}
\frac{\partial^{2} \theta}{\partial \alpha \partial g} & =\frac{1-\omega}{2 \omega X\left(1-\pi_{X}\right)^{2}} \frac{\partial \pi_{X}}{\partial \alpha} \\
\frac{\partial^{2} \theta}{\partial \alpha \partial \omega} & =-\frac{g}{2 \omega^{2} X\left(1-\pi_{X}\right)^{2}} \frac{\partial \pi_{X}}{\partial \alpha} .
\end{aligned}
$$

If $\alpha<\alpha^{*}, \frac{\partial \pi_{X}}{\partial \alpha}>0$ and so $\frac{\partial^{2} \theta}{\partial \alpha \partial g}>0$ and $\frac{\partial^{2} \theta}{\partial \alpha \partial \omega}<0$. If $\alpha>\alpha^{*}$, all inequalities are reversed. We also have

$$
\frac{\partial^{2} \theta}{\partial \alpha \partial c}=\frac{(1-\omega) g}{2 \omega X\left(1-\pi_{X}\right)^{2}} \frac{\partial^{2} \pi_{X}}{\partial \alpha \partial c}+\frac{(1-\omega) g}{\omega X\left(1-\pi_{X}\right)^{3}} \frac{\partial \pi_{X}}{\partial c} \frac{\partial \pi_{X}}{\partial \alpha},
$$

where

$$
\begin{aligned}
\frac{\partial \pi_{X}}{\partial c} & =-\frac{1-e^{-\lambda \beta}}{1+e^{-\lambda \beta}}\left(\frac{\mu^{2}}{c}\right)=\frac{-2 \pi_{X}+1}{c}<0, \\
\frac{\partial^{2} \pi_{X}}{\partial \alpha \partial c} & =-\frac{\partial \pi_{X}}{\partial \alpha} \frac{2}{c}
\end{aligned}
$$

If $\alpha<\alpha^{*}, \frac{\partial \pi_{X}}{\partial \alpha}>0$. Thus, $\frac{\partial^{2} \pi_{X}}{\partial \alpha \partial c}<0$ and $\frac{\partial \pi_{X}}{\partial c} \frac{\partial \pi_{X}}{\partial \alpha}<0$, so $\frac{\partial^{2} \theta}{\partial \alpha \partial c}<0$. If $\alpha>\alpha^{*}$, all inequalities are reversed. If $\frac{\partial \theta}{\partial \alpha}=0$, all cross-partials are zero. Hence, Proposition 2 states the cross-partials in terms of inequalities. Q.E.D.

Proof of Proposition 3: From equation (7), the measure of market efficiency is

$$
\pi_{X}=\frac{1}{2}\left(\mu^{2} \frac{1-e^{-\lambda \beta}}{1+e^{-\lambda \beta}}+1\right)
$$

If $\alpha \leq \frac{\nu}{\nu+1}$, then $\beta=\alpha$ and so $\mu=\frac{\alpha X}{4 c}$. Let $J=e^{-\frac{\alpha}{\nu(1-\alpha)}}$. The derivative with respect to $\nu$ is:

$$
\frac{\partial \pi_{X}}{\partial \nu}=-\frac{\mu^{2} J \frac{\alpha \lambda}{\nu}}{(1+J)^{2}}<0
$$

which is the negative camouflage effect. Thus, market efficiency is maximized at the lowest possible $\nu$. If $\alpha \leq \frac{\nu}{\nu+1}$, then $\nu \geq \frac{\alpha}{1-\alpha}$ and so the lowest possible $\nu$ is $\frac{\alpha}{1-\alpha}$.

If $\alpha>\frac{\nu}{\nu+1}$, then $\beta=\frac{1}{\lambda}$ and so $\mu=\frac{X}{4 c \lambda}$, which is increasing in $\nu$, that is, $\frac{\partial \mu}{\partial \nu}>0$. Differentiating (A.4) with respect to $\nu$ gives

$$
\mu \frac{1-e^{-1}}{1+e^{-1}} \frac{\partial \mu}{\partial \nu}>0
$$

which reflects the beneficial effects of liquidity on effort. If $\alpha>\frac{\nu}{\nu+1}$, then $\nu<\frac{\alpha}{1-\alpha}$ and so the highest possible $\nu$ is $\frac{\alpha}{1-\alpha}$. In both cases, $\nu=\frac{\alpha}{1-\alpha}$ maximizes market efficiency $\pi_{X}$. From equation (11), increasing $\pi_{X}$ in turn augments $\theta$. Q.E.D. 
Proof of Proposition 4: Dropping constants, B's objective function (12) becomes

$$
\beta^{2}\left(\frac{e^{-\lambda \beta}}{1+e^{-\lambda \beta}}-\frac{1}{4}\right)
$$

We first prove that $\alpha_{P}^{*} \leq \frac{\nu}{\nu+1}$. If $\alpha>\frac{\nu}{\nu+1}$, then $\beta=\nu(1-\alpha)$ and $\lambda \beta=1$. Hence, (A.5) becomes

$$
\nu^{2}(1-\alpha)^{2}\left(\frac{e^{-1}}{1+e^{-1}}-\frac{1}{4}\right),
$$

which is decreasing in $\alpha$. Thus, $B$ will never choose $\alpha>\frac{\nu}{\nu+1}$. If $\alpha \leq \frac{\nu}{\nu+1}$, then $\beta=\alpha$ and the first-order condition of (A.5) is

$$
F(\nu, \alpha)=K\left[2-\frac{\alpha}{\nu(1+J)(1-\alpha)^{2}}\right]-\frac{1}{2}=0,
$$

where $K=\frac{J}{J+1}$ and $J=e^{-\frac{\alpha}{\nu(1-\alpha)}}$ as before. At $\alpha=\frac{\nu}{\nu+1}, J=e^{-1}$ and so (A.5) becomes

$$
\frac{e^{-1}}{e^{-1}+1}\left[2-\frac{\nu+1}{1+e^{-1}}\right]-\frac{1}{2}
$$

which is negative for all $\nu \in[0,1]$. Thus, $\alpha_{P}^{*}$ is strictly less than $\frac{\nu}{\nu+1}$.

Returning to equation (A.6), an increase in $\nu$ augments $J$ and thus also $K$. In addition, the term in square brackets rises, and so $\frac{\partial F}{\partial \nu}>0$. An increase in $\alpha$ reduces $J$ and thus also $K$. In addition, the term in square brackets falls, and so $\frac{\partial F}{\partial \alpha}<0$. Since

$$
\frac{\partial F}{\partial \nu}+\frac{\partial F}{\partial \alpha} \frac{\partial \alpha}{\partial \nu}=0
$$

we have $\frac{\partial \alpha_{P}^{*}}{\partial \nu}>0$.

From equation (11), investment $\theta$ is monotonic in market efficiency $\pi_{X}$. In turn,

$$
\pi_{X}=\frac{1}{2}\left(\frac{\alpha_{P}^{* 2} X^{2}}{16 c^{2}} \frac{1-e^{-\frac{\alpha_{P}^{*}}{\nu\left(1-\alpha_{P}^{*}\right)}}}{1+e^{-\frac{\alpha_{P}^{*}}{\nu\left(1-\alpha_{P}^{*}\right)}}}+1\right)
$$

In addition to its positive effect on $\pi_{X}$ through augmenting $\alpha_{P}^{*}, \nu$ also has a direct negative effect, the camouflage effect. We must therefore prove that the first effect dominates. For brevity, I write $\alpha$ instead of $\alpha_{P}^{*}$ in what follows. We drop constants in equation (A.7) and define

$$
G(\nu, \alpha(\nu))=\alpha^{2} \frac{1-e^{-\frac{\alpha}{\nu(1-\alpha)}}}{1+e^{-\frac{\alpha}{\nu(1-\alpha)}}} .
$$

Differentiating $G$ with respect to $\nu$ yields

$$
\frac{d G}{d \nu}=2 \alpha\left[\frac{1-J}{1+J} \frac{\partial \alpha}{\partial \nu}+\frac{\alpha J}{\nu(1+J)^{2}(1-\alpha)^{2}} \frac{\partial \alpha}{\partial \nu}-\frac{\alpha J}{\nu(1+J)^{2}(1-\alpha)} \frac{\alpha}{\nu}\right]
$$


From equation (A.6) above, we calculate

$$
\begin{aligned}
\frac{\partial F}{\partial \nu} & =\frac{1}{(1+J)^{2}} \frac{\partial J}{\partial \nu}\left[2-\frac{\alpha}{\nu(1+J)(1-\alpha)^{2}}\right]+K \frac{\alpha}{\nu(1+J)^{2}(1-\alpha)^{2}} \frac{\partial J}{\partial \nu}+K \frac{\alpha}{\nu^{2}(1+J)(1-\alpha)^{2}} \\
-\frac{\partial F}{\partial \alpha} & =-\frac{1}{(1+J)^{2}} \frac{\partial J}{\partial \alpha}\left[2-\frac{\alpha}{\nu(1+J)(1-\alpha)^{2}}\right]-K \frac{\alpha}{\nu(1+J)^{2}(1-\alpha)^{2}} \frac{\partial J}{\partial \alpha}+K \frac{1}{\nu(1+J)} \frac{1+\alpha}{(1-\alpha)^{3}}
\end{aligned}
$$

The ratio of the first term of $\frac{\partial F}{\partial \nu}$ to the first term of $-\frac{\partial F}{\partial \alpha}$ is

$$
-\frac{\partial J}{\partial \nu} / \frac{\partial J}{\partial \alpha}=(1-\alpha) \frac{\alpha}{\nu}
$$

The ratio of the second terms is also (A.8). The ratio of the third terms is $\frac{1-\alpha}{1+\alpha} \frac{\alpha}{\nu}$. Therefore,

$$
\frac{\partial \alpha}{\partial \nu}=-\frac{\partial F}{\partial \nu} / \frac{\partial F}{\partial \alpha}>\frac{1-\alpha}{1+\alpha} \frac{\alpha}{\nu}
$$

Dropping the constant $2 \alpha$, we have

$$
\frac{d G}{d \nu}>\frac{\alpha}{(1+J)(1+\alpha) \nu}\left[(1-J)(1-\alpha)-\frac{\alpha^{2} J}{\nu(1+J)(1-\alpha)}\right]
$$

It is sufficient to prove that the term in square brackets is positive. By Taylor expansion,

$$
J=e^{-\frac{\alpha}{\nu(1-\alpha)}}<1-\frac{\alpha}{\nu(1-\alpha)}+\frac{\alpha^{2}}{2 \nu^{2}(1-\alpha)^{2}},
$$

and so

$$
(1-J)(1-\alpha)-\frac{\alpha^{2} J}{\nu(1+J)(1-\alpha)}>\left[\frac{\alpha}{\nu(1-\alpha)}-\frac{\alpha^{2}}{2 \nu^{2}(1-\alpha)^{2}}\right](1-\alpha)-\frac{\alpha^{2} J}{\nu(1+J)(1-\alpha)} .
$$

Dropping $\frac{\alpha}{\nu(1-\alpha)}$, we obtain

$$
\left[1-\frac{\alpha}{2 \nu(1-\alpha)}\right](1-\alpha)-\frac{\alpha J}{(1+J)}
$$

Since $\alpha<\frac{\nu}{\nu+1} \leq \frac{1}{2}$, we have $\frac{\alpha}{2 \nu(1-\alpha)}<\frac{1}{2}$. Therefore,

$$
\left[1-\frac{\alpha}{2 \nu(1-\alpha)}\right](1-\alpha)>\left(1-\frac{1}{2}\right) \frac{1}{2}=\frac{1}{4}
$$

In addition, since $\alpha<\frac{1}{2}$ and $J \leq 1$, we also have

$$
\frac{\alpha J}{(1+J)}<\frac{1}{4}
$$

Hence, (A.9) and thus $\frac{d G}{d \nu}$ are positive. Therefore, $\pi_{X}$ and $\theta$ are increasing in $\nu$. Q.E.D. 


\begin{tabular}{|c|c|c|}
\hline$t=1$ & $t=2$ & $t=3$ \\
\hline \multirow[t]{3}{*}{$\begin{array}{l}\text { Public signal } s \in \\
\left\{\mathrm{S}_{\mathrm{g}}, \mathrm{S}_{\mathrm{b}}\right\} \text { released }\end{array}$} & $\begin{array}{l}\text { Blockholder exerts } \\
\text { monitoring effort } \mu \text {, } \\
\text { receives signal } i \in\left\{\mathrm{i}_{\mathrm{g}}, \mathrm{i}_{\mathrm{b}}\right\} \text {, } \\
\text { and sells } \mathrm{b} \in[0, \alpha]\end{array}$ & $\mathrm{V}$ is publicly revealed \\
\hline & $\begin{array}{l}\text { Liquidity traders demand } \\
\mathrm{u} \sim \exp (\lambda)\end{array}$ & \\
\hline & $\begin{array}{l}\text { Market maker observes } d \\
=b+u \text { and sets } P= \\
E[V \mid d, s]\end{array}$ & \\
\hline
\end{tabular}

Figure 1. Timeline of the model. 


\section{REFERENCES}

Admati, Anat, and Paul Pfleiderer, 2009, The "Wall Street Walk" and shareholder activism: Exit as a form of voice, Review of Financial Studies, forthcoming.

Aghion, Philippe, Patrick Bolton, and Jean Tirole, 2004, Exit options in corporate finance: Liquidity versus incentives, Review of Finance 8, 327-353.

Amihud, Yakov, and Kefei Li, 2006, The declining information content of dividend announcements and the effects of institutional holdings, Journal of Financial and Quantitative Analysis 41, 637-660.

Armour, John, Bernard Black, Brian Cheffins, and Richard Nolan, 2007, Private enforcement of corporate law: An empirical comparison of the U.S. and U.K., Working paper, European Corporate Governance Institute.

Atanassov, Julian, 2008, Do hostile takeovers stifle innovation? Evidence from antitakeover legislation and corporate patenting, Working paper, University of Oregon.

Barclay, Michael, and Clifford Holderness, 1989, Private benefits from control of public corporations, Journal of Financial Economics 25, 371-395.

Barclay, Michael, and Clifford Holderness, 1991, Negotiated block trades and corporate control, Journal of Finance 46, 861-878.

Barlevy, Gadi, and Pietro Veronesi, 2000, Information acquisition in financial markets, Review of Economic Studies 67, 79-90.

Bartov, Eli, Suresh Radhakrishnan, and Itzhak Krinsky, 2000, Investor sophistication and patterns in stock returns after earnings announcements, The Accounting Review 75, 43-63.

Baysinger, Barry, Rita Kosnik, and Thomas Turk, 1991, Effects of board and ownership structure on corporate R\&D strategy, Academy of Management Journal 34, 205-214.

Becht, Marco, Julian Franks, Colin Mayer, and Stefano Rossi, 2009, Returns to shareholder activism: Evidence from a clinical study of the Hermes U.K. Focus Fund, Review of Financial Studies, forthcoming.

Becker, Bo, Henrik Cronqvist, and Rüdiger Fahlenbrach, 2008, Estimating the effect of large shareholders using a geographic instrument, Working paper, University of Illinois at UrbanaChampaign. 
Berle, Adolf, and Gardner Means, 1932, The Modern Corporation and Private Property (MacMillan, New York, NY).

Bernhardt, Dan, Burton Hollifield and Eric Hughson, 1995, Investment and insider trading, Review of Financial Studies 8, 501-543.

Bhide, Amar, 1993, The hidden costs of stock market liquidity, Journal of Financial Economics 34, 31-51.

Black, Bernard, 1990, Shareholder passivity reexamined, Michigan Law Review 89, 520-608.

Boehmer, Ekkehart, and Eric Kelley, 2009, Institutional investors and the informational efficiency of prices, Review of Financial Studies, forthcoming.

Bolton, Patrick, and Ernst-Ludwig von Thadden, 1998, Blocks, liquidity, and corporate control, Journal of Finance 53, 1-25.

Brav, Alon, and Richmond Mathews, 2008, Empty voting and the efficiency of corporate governance, Working paper, Duke University.

Brockman, Paul, and Xuemin (Sterling) Yan, 2009, Block ownership and firm-specific information, Journal of Banking and Finance 33, 308-316.

Burkart, Mike, Denis Gromb, and Fausto Panunzi, 1997, Large shareholders, monitoring, and the value of the firm, Quarterly Journal of Economics 112, 693-728.

Burns, Natasha, Simi Kedia, and Marc Lipson, 2008, Institutional ownership and monitoring: Evidence from financial reporting practices, Working paper, University of Georgia.

Bushee, Brian, 1998, The influence of institutional investors on myopic R\&D investment behavior, The Accounting Review 73, 305-333.

Bushee, Brian, and Theodore Goodman, 2007, Which institutional investors trade based on private information about earnings and returns? Journal of Accounting Research 45, 289-321.

Chen, Xia, Jarrad Harford, and Kai Li, 2007, Monitoring: Which institutions matter? Journal of Financial Economics 86, 279-305.

Cronqvist, Henrik, and Rüdiger Fahlenbrach, 2009, Large shareholders and corporate policies, Review of Financial Studies, forthcoming.

Dechow, Patricia, Richard Sloan, and Amy Sweeney, 1996, Causes and consequences of earnings manipulation: An analysis of firms subject to enforcement actions by the SEC, Contemporary Accounting Research 13, 1-36. 
Demsetz, Harold, and Kenneth Lehn, 1985, The structure of corporate ownership: Causes and consequences, Journal of Political Economy 93, 1155-1177.

Edmans, Alex, 2007, Leverage, ownership concentration, and the tension between liquidation and investment, Working paper, University of Pennslyvania.

Edmans, Alex, 2009, Does the stock market fully value intangibles? Employee satisfaction and equity prices, Working paper, University of Pennslyvania.

Edmans, Alex, and Gustavo Manso, 2009, Governance through exit and voice: A theory of multiple blockholders, Working paper, University of Pennslyvania.

Fang, Vivian, Thomas Noe and Sheri Tice, 2008, Stock market liquidity and firm value, Working paper, Tulane University

Farber, David, 2005, Restoring trust after fraud: Does corporate governance matter? The Accounting Review 80, 539-561.

Faure-Grimaud, Antoine, and Denis Gromb, 2004, Public trading and private incentives, Review of Financial Studies 17, 985-1014.

Gallagher, David, Peter Gardner, and Peter Swan, 2008, Blockholder intervention versus threat of exit, Working paper, University of New South Wales.

Graham, John, Campbell Harvey, and Shivaram Rajgopal, 2005, The economic implications of corporate financial reporting, Journal of Accounting and Economics 40, 3-73.

Hansen, Gary, and Charles Hill, 1991, Are institutional investors myopic? A time-series study of four technology-driven industries, Strategic Management Journal 12, 1-16.

Heflin, Frank, and Kenneth Shaw, 2000, Blockholder ownership and market liquidity, Journal of Financial and Quantitative Analysis 35, 621-633.

Holderness, Clifford, 2009, The myth of diffuse ownership in the United States, Review of Financial Studies, forthcoming.

Holmstrom, Bengt, and Jean Tirole, 1993, Market liquidity and performance monitoring, Journal of Political Economy 101, 678-709.

Johnson, Shane, Harley Ryan, and Yisong Tian, 2009, Managerial incentives and corporate fraud: The source of incentives matter, Review of Finance, forthcoming.

Kahn, Charles, and Andrew Winton, 1998, Ownership structure, speculation, and shareholder intervention, Journal of Finance 53, 99-129. 
Kaplan, Steven, and Bernadette Minton, 2006, How has CEO turnover changed? Increasingly performance sensitive boards and increasingly uneasy CEOs, Working paper, University of Chicago.

Kole, Stacey, 1997, The complexity of compensation contracts, Journal of Financial Economics 43, 79-104.

Kyle, Albert, 1985, Continuous auctions and insider trading, Econometrica 53, 1315-1335.

Kyle, Albert, and Jean-Luc Vila, 1991, Noise trading and takeovers, RAND Journal of Economics 22, 54-71.

La Porta, Rafael, Florencio Lopez-de-Silanes, and Andrei Shleifer, 1999, Corporate ownership around the world, Journal of Finance 54, 471-517.

Lee, Peggy, 2005, A comparison of ownership structures and innovations of U.S. and Japanese firms, Managerial and Decision Economics 26, 39-50.

Lee, Peggy, and Hugh O’Neill, 2003, Ownership structures and R\&D investments of U.S. and Japanese firms: Agency and stewardship perspectives, Academy of Management Journal $46,212-225$.

Lowenstein, Louis, 1988, What's Wrong With Wall Street? Short-Term Gain and the Absentee Shareholder (Addison-Wesley, Reading, MA).

Manne, Henry, 1966, Insider Trading and the Stock Market (Free Press, New York, NY).

Maug, Ernst, 1998, Large shareholders as monitors: Is there a trade-off between liquidity and control? Journal of Finance 53, 65-98.

Maug, Ernst, 2002, Insider trading legislation and corporate governance, European Economic Review 46, 1569-1597.

McCahery, Joseph, Zacharias Sauntner, and Laura Starks, 2008, Behind the scenes: The corporate governance preferences of institutional investors, Working paper, University of Amsterdam.

Merton, Robert, 1987, A simple model of capital market equilibrium with incomplete information, Journal of Finance 42, 483-510.

Mikkelson, Wayne, and Megan Partch, 1985, Stock price effects and costs of secondary distributions, Journal of Financial Economics 14, 165-194.

Murphy, Kevin, 2003, Stock-based pay in new economy firms, Journal of Accounting and 
Economics 34, 129-147.

Narayanan, M. P., 1985, Managerial incentives for short-term results, Journal of Finance 40, 1469-1484.

Pagano, Marco and Ailsa Röell, 1998, The choice of stock ownership structure: Agency costs, monitoring, and the decision to go public, Quarterly Journal of Economics 113, 187-225.

Parrino, Robert, Richard Sias, and Laura Starks, 2003, Voting with their feet: Institutional ownership changes around forced CEO turnover, Journal of Financial Economics 68, 3-46.

Peng, Lin, and Ailsa Roell, 2008, Executive pay, earnings manipulation and shareholder litigation, Review of Finance 12, 141-184.

Porter, Michael, 1992, Capital disadvantage: America's failing capital investment system, Harvard Business Review 70, 65-82.

Roe, Mark, 1994, Strong Managers, Weak Owners: The Political Roots of American Corporate Finance (Princeton University Press, Princeton, NJ).

Rubin, Amir, 2007, Ownership level, ownership concentration and liquidity, Journal of Financial Markets 10, 219-248.

Scharfstein, David, and Jeremy Stein, 1990, Herd behavior and investment, American Economic Review 80, 465-479.

Scholes, Myron, 1972, The market for securities: Substitution versus price pressure and the effects of information on share prices, Journal of Business 45, 179-211.

Sias, Richard, Laura Starks, and Sheridan Titman, 2006, Changes in institutional ownership and stock returns: Assessment and methodology, Journal of Business 79, 2869-2910.

Shleifer, Andrei, and Robert Vishny, 1986, Large shareholders and corporate control, Journal of Political Economy 94, 461-488.

Stein, Jeremy, 1988, Takeover threats and managerial myopia, Journal of Political Economy $46,61-80$.

Stein, Jeremy, 1989, Efficient capital markets, inefficient firms: A model of myopic corporate behavior, Quarterly Journal of Economics 104, 655-669.

Stein, Jeremy, 1996, Rational capital budgeting in an irrational world, Journal of Business $69,429-455$.

Stiglitz, Joseph, 1981, Pareto optimality and competition, Journal of Finance 36, 235-251. 
Thurow, Lester, 1993, Head to Head: The Coming Economics Battle Among Japan, Europe and America (Warner Books, New York, NY).

Van Nieuwerburgh, Stijn, and Laura Veldkamp, 2008, Information acquisition and underdiversification, Working paper, New York University.

Wahal, Sunil, and John McConnell, 2000, Do institutional investors exacerbate managerial myopia? Journal of Corporate Finance 6, 307-329.

Wruck, Karen, 1989, Equity ownership concentration and firm value: Evidence from private equity financings, Journal of Financial Economics 23, 3-28.

Yan, Xuemin, and Zhe Zhang, 2009, Institutional investors and equity returns: Are shortterm institutions better informed? Review of Financial Studies, forthcoming.

Zingales, Luigi, 2000, In search of new foundations, Journal of Finance 55, 1623-1653. 